\title{
How can remote sensing techniques help monitoring the vine and maximize the terroir potential?
}

\author{
Cecile Tondriaux ${ }^{1}$, Anne Costard ${ }^{1}$, Corinne Bertin ${ }^{1}$, Sylvie Duthoit ${ }^{1}$, Jérôme Hourdel $^{2}$ and Jacques Rousseau ${ }^{2}$ \\ ${ }^{1}$ TerraNIS SAS, 10 Avenue de l'Europe, 31520 Ramonville, France \\ ${ }^{2} \mathrm{ICV}$, La Jasse de Maurin, 34970 LATTES, France
}

\begin{abstract}
In each winegrowing region, the winegrower tries to value its terroir and the oenologists do their best to produce the best wine. Thanks to new remote sensing techniques, it is possible to implement a segmentation of the vineyard according to the qualitative potential of the vine stocks and make the most of each terroir to improve wine quality. High resolution satellite images are processed in several spectral bands and algorithms set-up specifically for the Oenoview service allow to estimate vine vigour and a heterogeneity index that, used together, directly reflect the vineyard oenological potential. This service is used in different terroirs in France (Burgundy, Languedoc, Bordeaux, Anjou) and in other countries (Chile, Spain, Hungary and China). From this experience, we will show how remote sensing can help managing vine and wine production in all covered terroirs. Depending on the winegrowing region and its specificities, its use and results present some differences and similarities that we will highlight. We will give an overview of the method used, the advantage of implementing field intra-or inter-selection and how to optimize the use of amendment and sampling strategy as well as how to anticipate the whole vineyard management.
\end{abstract}

\section{Precision viticulture: why and for whom}

In a context of growing competition on international markets, it becomes of utmost importance to help winegrowers improve profitability and maximize wine quality. The use of precision viticulture is a step in this direction. Multi-spectral satellite and aerial images are frequently used to estimate vegetation indices or biophysical parameters linked to vegetation status (biomass, nutrient deficiencies, water stress status, or health status) [1], thus allowing to map intra and inter-field spatial variability [2]. The consideration of this particularly high variability within vineyards is crucial for a better management on all aspects: technical to maximize agronomic performances, economical to optimize profitability and environmental to limit the impact of cultural practices.

Nowadays, four concrete main uses of precision viticulture can be highlighted; all answering wineries or winemakers needs:

- $\quad$ Selective harvesting: an allotment based on vine vigor and heterogeneity indicators is performed to gather parcels or part of parcels with similar organoleptic properties. The efficiency of the vine field selection is improved to achieve specific production goals.

- $\quad$ Reduction of fertilization costs : fertilizer inputs are adjusted according to the vigor areas delineated inside each vine plot, leading to optimized and rational fertilization scheme.

- Adaptation of cultural practices to each vintage with the aim of homogenizing vine plots.

- Optimize sampling strategy to guide field observations such as maturity controls, yield estimation or sampling to ease the technician work.

In France, several operational solutions exist and are based on multispectral UAV, aerial or satellite imagery. Most of these solutions use vegetation indices such as NDVI (Normalize difference vegetation index) to reflect vine vigor (such as Fruition Analytics, EarthLab \& Millesime), excepted (Enoview ${ }^{\circledR}$ which generates vine biophysical parameters such as FCover (Fraction of green cover vegetation). 


\section{The CEnoview ${ }^{\circledR}$ service}

\subsection{Purpose and scope of the CEnoview ${ }^{\circledR}$ service}

Enoview ${ }^{\circledR}$ is a comprehensive precision viticulture service, available worldwide, helping winegrowers improve profitability and wine quality. The Enoview ${ }^{\circledR}$ service is based on the analyses of satellite imagery associated with an expertise in viticulture and winemaking. Its development has been initialized in 2007 by Airbus Defence \& Space and the ICV group; Since 2014, Enoview ${ }^{\circledR}$ is commercialized by TerraNIS, which brings expertise in satellite imagery analyze and supply of value-added products, in partnership with the ICV group that brings its knowledge in viticulture and winemaking.

The Enoview ${ }^{\circledR}$ cartography measures the variability of vine vigor through satellite imagery and the level of internal variability of each vineyard and vine plot. This information is then analyzed and formatted in order to help users make the good decisions. Zoned maps are used to improve agricultural practices such as field selection, fertilization or harvest. On a large scale, groups of vineyards presenting the same characteristics can be created to improve harvest organization.

Enoview ${ }^{\circledR}$ has been sold since 2008 mainly in France but also in Morocco, Japan, China, Chile, Hungary and Spain. For the year 2016 for example, Enoview ${ }^{\circledR}$ was sold in France for a total of 5500 hectares concerning around 290 wineries. In the perspective of addressing other countries, which is a key strategic goal for TerraNIS development, demonstrations are still going on in Italy and Greece particularly.

\subsection{Methodology}

The main steps of the process can be seen in Figure 1 . Once information on the area(s) of interest has been provided by the customer (fields contours, grape variety, practices etc), at least one satellite image is acquired at the veraison stage, but more acquisitions can be envisaged if a vegetation monitoring is required. (Enoview ${ }^{\circledR}$ is based on optical satellite imagery with, most of the time, a spatial resolution less or equal to $1 \mathrm{~m} 50$ (Spot6/7, Pleiades, ...). Images -which embed several spectral bands from visible to near infra-red - are processed by the Overland software suite (developed and maintained by Airbus Defence \& Space). It retrieves physical characteristics from spectral information (biophysical processing) using state-of-the-art reflectance models of vegetation (PROSPECT/SAIL model [3]), integrating the atmospheric correction of the satellite image (based on LOWTRAN model [4]) and using advanced numerical techniques to perform model inversion.

The retrieved biophysical parameters such as FCover (Fraction of green cover vegetation) which directly reflects vine vigor is known to be robust, without any bias due to agricultural practice or atmospheric conditions, and reproducible enough to allow the absolute characterization of a parcel, and thus the spacialization of agronomic advices.

Three to four weeks before harvest, vine vigor maps and corresponding statistical indicators are delivered in different kinds of formats according to user needs (GIS compatible format, kml, pdf, posters, ...). A Smartphone application allows to display Enoview ${ }^{\circledR}$ products anywhere and to enrich them with in-field reports. All along these steps, appropriate and customized recommendations and on-site visits are proposed.

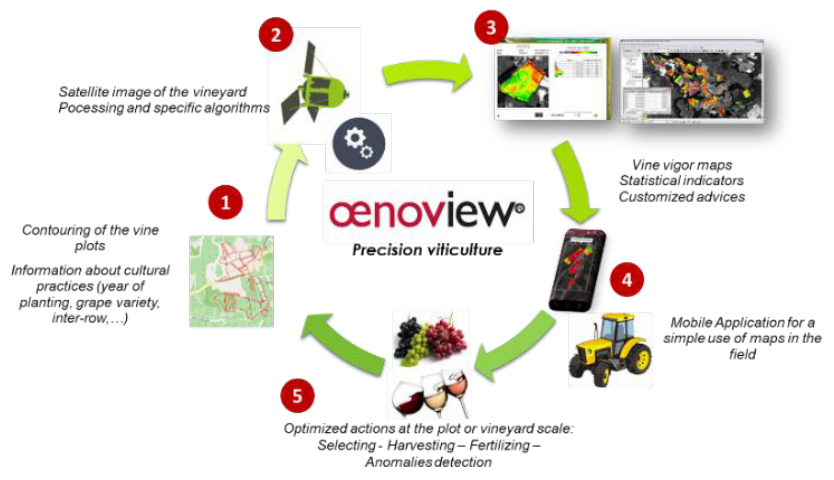

Figure 1 : Main steps of the Enoview ${ }^{\circledR}$ service.

\subsection{Main benefits for the wine industry}

Enoview ${ }^{\circledR}$ has a threefold benefit: decrease production costs by optimizing farming practices, reduce environmental impact by limiting chemical inputs and improve both quality and productivity of the vineyard.

If you are a winegrower, Enoview ${ }^{\circledR}$ offers you the opportunity to improve the profitability of your vineyard thanks to an accurate mapping of each field. Image processing algorithms combined with the oenological know-how make possible to extract useful indicators for a better management of the harvest and an optimization of agricultural practices (fertilization, irrigation, health protection etc). Areas with anomalies (diseases or nutrient deficiencies for instance) can be early detected to make appropriate decisions.

If you manage a winery, Enoview ${ }^{\circledR}$ provides you with an instantaneous and large-scale characterization of the qualitative potential of the vineyard parcels. An allotment based on oenological quality indicators is performed to gather parcels or part of parcels with similar organoleptic properties. You can then improve the efficiency of your vine parcel selection to achieve specific production goals.

The following section show examples of uses of Enoview®. 


\section{Concrete examples of uses}

\subsection{For a simple and reliable field selection}

In the Languedoc winemaking region, where several big wineries or winemakers (i.e Vinovalie, Canet winery, Ouveillan winery, Les Grands Chais de France, ...) use Enoview ${ }^{\circledR}$ since several years, one of its main uses is the characterization of the qualitative potential of the vineyard parcels for parcels selection. According to the winery production goals, an allotment based on vigor and heterogeneity indicators is performed, leading to an improvement of the efficiency of the field selection. In the example shown in Figure $2:$, fields with high vigor were selected to make Rosé wine; with adapted winemaking methods, homogeneous parcels with moderate vigor were selected to give full-bodied red wine and parcels with moderate vigor and high heterogeneity gave a fruity red wine. Two complementary red wine styles are produced and a regularity from one year to another is thus reached.

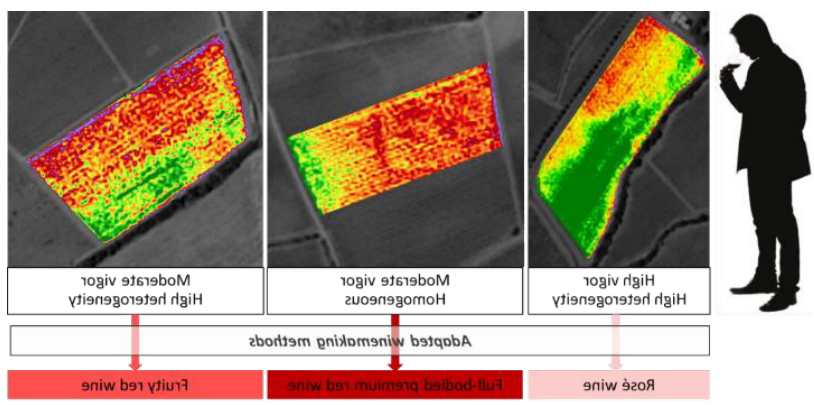

Figure 2: Illustration of the use of the precision viticulture service Enoview ${ }^{\circledR}$ in the Languedoc winemaking region (France) for field selection.

\subsection{To reduce fertilization costs}

The Grands Chais de France (GCF) group is one of the largest vineyard owners in the world. The group currently owns 33 wineries in many wine-growing areas of France and 1,500 hectares of vines. One of the main objective of GCF when choosing to map vine vigor with Enoview ${ }^{\circledR}$ in 2016 and 2017 for an area of 600 hectares was to be thrifty and eco-aware when applying fertilizers and phytosanitary products, improving their profitability in the meantime. Adapted zoned vine vigor products with 4 to 8 zones per vine plot, associated with fertilizer spreaders capable of variable rate application, allowed them to set up a rational fertilization schemes (Figure 3). Even without such a sophisticated equipment attached to a tractor, it is possible to target fertilization input differentially, for example by speeding up or slowing down tractor speed locally. The profitability or the fertilization scheme set up in 2017 still has to be clearly evaluated but previous uses of such maps in the Bordeaux winemaking region (Châteaux Castel and
Château Fayau for example) disclosed that 10 to $30 \%$ saving has been made on the fertilization costs.

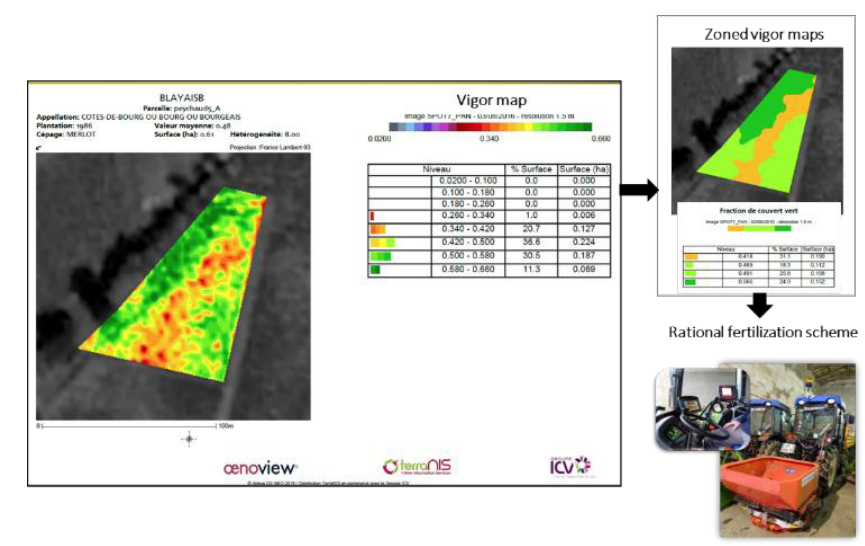

Figure 3 : Use of Enoview $\circledR$ zoned vine vigor maps obtained from satellite image acquired at veraison stage in 2016 to set up a rational fertilization scheme (Grand Chais de France).

\subsection{To monitor vineyard evolution}

The "Château Fortia» is one of the oldest winery of Châteauneuf-du-Pape in the Rhone winemaking region. Over its 30 hectares, Fortia has always developed integrated vineyard practices and $\left(\right.$ Enoview ${ }^{\circledR}$ is used since several years as a decision support tool for diverse applications: parcel selection, vineyard restructuration scheme or reduction of intra-field variability for example. Moreover, the monitoring available (

Figure 4) allowed them to understand the vintage effect, to quantify the impacts of changes in the agricultural practices and to adjust practices to each vintage.

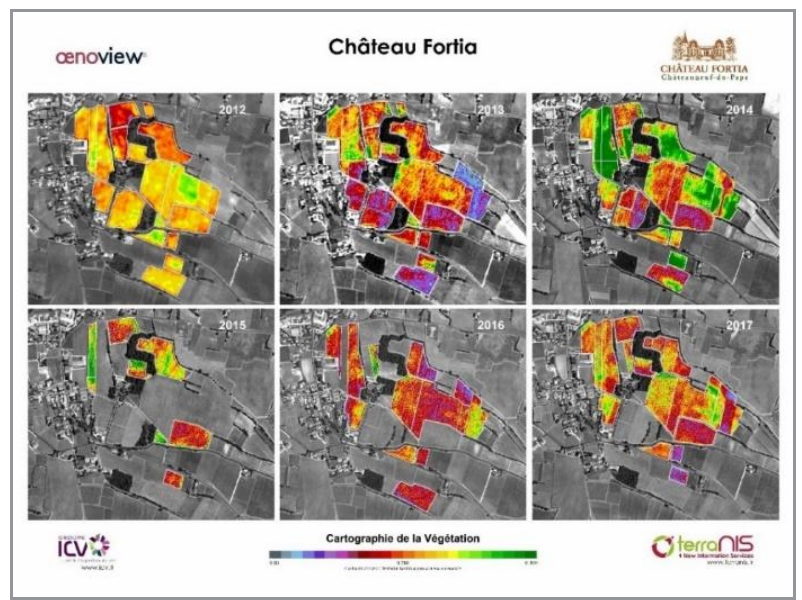

Figure 4 : Example of vineyard evolution monitoring with the precison viticulture service Enoview ${ }^{\circledR}$ between 2012 and 2017 in the Rhone winemaking region (France). 


\subsection{As a global decision tool}

In Chile, the use of such vigor maps is quite diverse. When big wineries (from 5.000 to 11.000 hectares) harvest all the vine mechanically and look for a tool to both detect anomalies and help them plan the harvest calendar at a plot level, others, smaller and dedicated to high quality wine, use the Oenoview maps combined with other measurement systems to detect at an early stage any kind of growth problem and early signs of water stress. They monitor the vegetation development thanks to several images, carefully analyse each area of heterogeneity at the pixel level, to then harvest all by hand, following a meticulous planning. Then, the maps are also used as a decision-making tool to plan their fertilization strategy, to define the quantity and spot the needier areas.

\subsection{To improve management of sub-field and inter-field variability}

With its high positive progression, the Apulia wine production has to cope with economic and environmental constraints. Improving wine quality and quantity while reducing environmental impacts and the use of chemical inputs is a key issue for the sustainability of Apulia vineyards. In this context, Enoview ${ }^{\circledR}$ was proposed in Apulia by Planetek, thanks to the Eugenius platforms network implemented in the frame of the Eugenius H2020 Copernicus project. In 2017, a first experimental pilot service was conducted for Tormaresca vineyard in Salento, an Apulian vinery property of the Antinori family. More than 200 hectares were monitored using very highresolution satellite images and agronomical in-situ dataset (grape variety and cultural practices). Several critical stages of the grape development were monitored, with a special focus during veraison stage (a few weeks before harvesting). Zoned maps were also produced to define homogeneous areas on which specific agricultural practices such as fertilization can be implemented. Finally, Enoview ${ }^{\circledR}$ supported Tormaresca wine-growers in managing sub-field and inter-field variability of the vine vigor (Figure ). Enoview ${ }^{\circledR}$ customer found satellite monitoring the most accurate and affordable survey method to support the production of high quality wine.

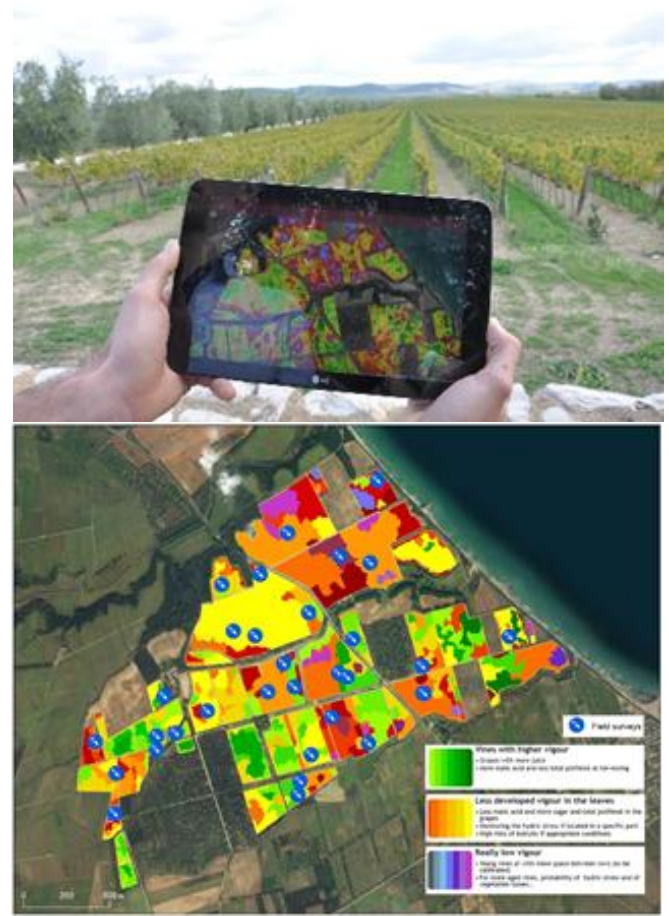

Figure 5: Vine vigor maps displayed on the Smartphone application (left) and homogeneous areas for harvest optimization and wine quality improvement defined by Enoview ${ }^{\circledR}$ (right) - Tormaresca Bocca di Lupo Vineyard in Minervino Murge (Apulia).

\section{Conclusion and evolutions to come}

Precision viticulture allows to estimate and map vine vegetation development through vegetation indices or biophysical parameters linked to vine vigor, highlighting then spatial variability within fields, but also at the entire vineyard scale. Concrete uses for wine cooperatives or wine growers are diverse but field selection, fertilization and vineyard monitoring are the main uses observed. The Oenoview ${ }^{\circledR}$ service, which was mainly proposed in France vineyards so far, is now addressing other countries. Customers' feedbacks, in France but also worldwide with the first conducted experimentations, are very positive (Figure ), proving that Oenoview ${ }^{\circledR}$ can be fully operational even in a new climate and soil environment.

TerraNIS also tries to constantly improve its portfolio of services to answer vineyards needs. TerraNIS is then currently working with partners to detect and characterize water stress in the vineyard, which is an important issue for the wine industry in France but also worldwide. The use of remote sensing imagery is coupled with in-situ measurements using the IoT technology. The objective is to optimize water resources, bringing the right amount of water at the right place, thus ensuring vine health and wine quality. 


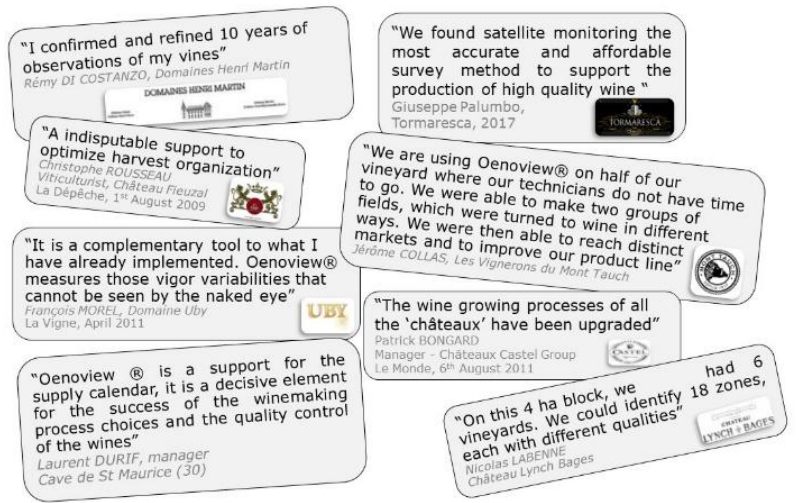

5 References

1. L.F. Johnson and al., 2003, J. Rousseau and al., 2008; C. Acevedo and al., 2007; D. Lamb and al., 2004

2. A. Hall et al., 2002, B.Tisseyre and al., 2007

3. PROSPECT/SAIL: S. Jacquemond and F. Baret, 1990; J.B. Feret et al, 2008; W. Verhoef, 1984

4. LOWTRAN : F. Kneizys and al, 1988
Figure 6: Examples of Oenoview Users' feedback 